\title{
New heterocyclization reactions with Fischer carbene complexes
}

\author{
José Barluenga* and Silvia Martínez \\ Instituto Universitario de Química Organometálica “Enrique Moles”, Unidad Asociada al \\ CSIC, Universidad de Oviedo, Julián Clavería 8, 33071-Oviedo, Spain \\ E-mail: barluenga@uniovi.es
}

\begin{abstract}
In this account, our recent contributions in the field of group 6 Fischer carbene complexes chemistry and their application toward the synthesis of carbocyclic and heterocyclic compounds are reviewed. Fischer carbenes participate in [2+1], [2+2], [3+2], [4+2], [4+3], [5+2] and [6+3] cycloadditions with a great variety of unsaturated systems. Additionally they constitute good Michael acceptors in the addition of different enolates, leading to the enantioselective formation of several cyclic systems as well as products derived from interesting multicomponent reactions.
\end{abstract}

Keywords: Fischer carbenes, cyclization, carbocycles, heterocycles, dienes, enolates, fulvenes

\section{Contents}

1. Introduction

2. Results and Discussion

2.1 Reactivity of Fischer carbene complexes toward enol ethers

2.2 Reactivity of Fischer carbene complexes toward dipolar systems

2.3 Reactivity of Fischer carbene complexes toward dienes and heterodienes

2.3.1 [4+2] Cycloadditions

2.3.2 [4+3] Cycloadditions

2.4 Reactivity of Fischer carbene complexes toward enolates

2.4.1 Addition of enolates to chiral alkenyl carbene complexes

2.4.2 Addition of chiral enolates to alkenyl carbene complexes

2.4.3 Cycloadditions with methyl ketone enolates

2.4.4 Multicomponent couplings of lithium enolates and allylmagnesium bromide

2.5 Reactivity of Fischer carbene complexes toward pentafulvenes 


\section{Introduction}

Fischer carbene complexes, particularly chromium and tungsten compounds, are highly valuable building blocks for the construction of complex organic molecules. ${ }^{1}$ On one hand, the insaturation conjugated with the carbene function in alkenyl and alkynyl complexes can participate in different [2+2], [3+2], [4+2] and [4+3] cycloadditions, as it will be commented in the first sections of the present review. Additionally, the presence of the carbene function in these complexes is responsible for an additional model of reactivity- specific for these systemswhich is based on the direct participation of the metal carbene carbon followed by a subsequent cyclization induced by a 1,2 migration of the metal fragment to the adjacent carbon atom.

\section{Results and Discussion}

\subsection{Reactivity of Fischer carbene complexes toward enol ethers}

The insaturation conjugated with the carbenic carbon in alkynyl complexes can participate in different cyclization reactions, leading to the formation of new Fischer carbenes. Thus, for example 1-metalla-1,3,5-hexatrienes have been synthesized by [2+2] cycloaddition of alkynylcarbenes 1 and enol ethers (Scheme 1). ${ }^{2}$ The newly formed carbene complexes 2 react with terminal alkynes in THF in a Dötz-like cyclization, giving cyclooctatrienones $\mathbf{3}$ in moderate yields. $^{3}$

A suitable mechanism for this transformation would involve the insertion of an alkyne molecule into the chromium-carbon double bond, leading to intermediate $\mathbf{I}$, followed by $\mathrm{CO}$ insertion to give the ketene complex II, as in the first steps of the Dötz reaction. This trienylketene intermediate undergoes an electrocyclic ring closure, promoted by the presence of the four-membered ring, affording the final product after decomplexation of the metal fragment.

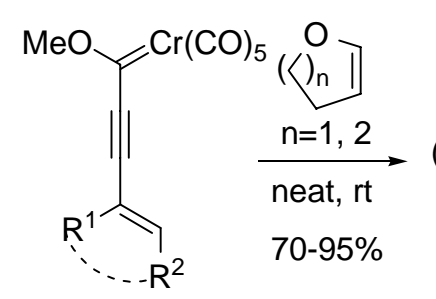

1

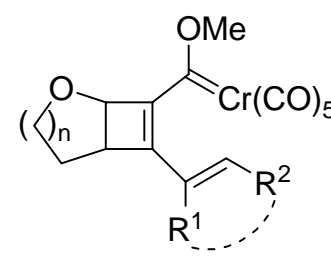

2

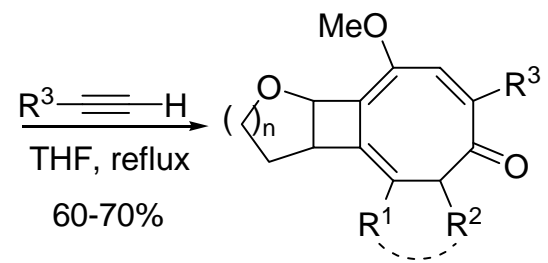

3
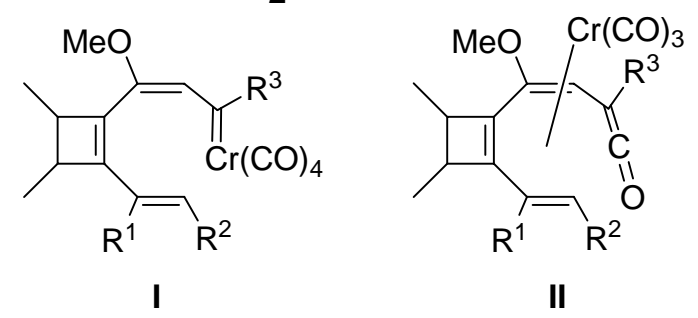

Scheme 1. [2+2] Cycloaddition of alkynyl carbenes 1 and enol ethers. 
Interestingly, when cyclooctatrienone 4 was allowed to stand in chloroform for then days, it evolved to the tetracyclic structure 5, obtained as a single diastereoisomer in $90 \%$ yield. This product derives from the six-electron electrocyclization of the starting trienyl system present in 4 and the hydrolysis of the resulting enol ether.

An epimerization of the $\alpha$-carbonyl stereocenter in $\mathbf{4}$ and the stereoselective cyclization of one of the epimeric ketones would probably account for the high diastereoselectivity observed.

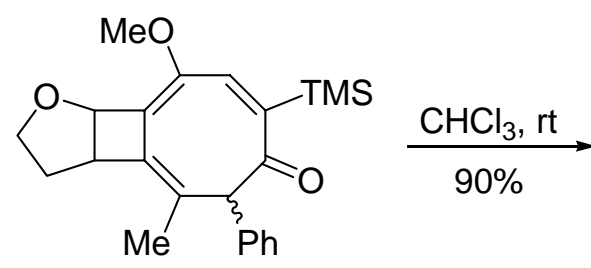

4

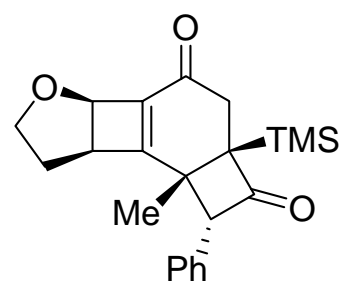

5

(one diastereoisomer)

Scheme 2. Evolution of a cyclooctatrienone in chloroform.

\subsection{Reactivity of Fischer carbene complexes toward dipolar systems}

Chiral, nonracemic carbene complexes derived from (-)-8-phenylmenthol have been widely used in diastereoselective processes. For instance, they allow the synthesis of 4,5-dihydro- $1 \mathrm{H}$ pyrazole esters 7 in the one-pot procedure shown in Scheme 3. ${ }^{4}$ Thus, the [3+2] cyclization reaction of alkenyl carbenes 6 with diazomethane derivatives in THF at room temperature, followed by BOC protection and subsequent oxidation of the carbene moiety leads to the corresponding $\Delta^{2}$-pyrazoline derivatives as single diastereomers in yields ranging between 55 and $79 \%$.

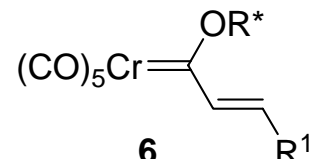

1. $\mathrm{R}^{2} \mathrm{CHN}_{2}$, THF, rt, 2-12 h

2. $(\mathrm{BOC})_{2} \mathrm{O}, \mathrm{NEt}_{3}, \mathrm{DMAP}$

3. Pyridine oxide

$\mathrm{R}^{1}=\mathrm{Ph}, 2$-furyl

$\mathrm{R}^{2}=\mathrm{H}, \mathrm{TMS}, \mathrm{CH}=\mathrm{CH}_{2}, \mathrm{Ph}$

$55-79 \% ; d r>95 / 5$

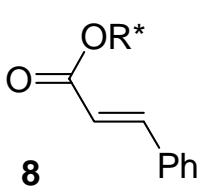

1. $\mathrm{TMSCHN}_{2}$, THF, reflux, 8 days

2. $(\mathrm{BOC})_{2} \mathrm{O}, \mathrm{NEt}_{3}, \mathrm{DMAP}$

$65 \% ; d r=60 / 40$

$\mathrm{R}^{\star} \mathrm{OH}=(-)-8-$ phenylmenthol

Scheme 3. [3+2] Cycloaddition of Fischer carbene complexes. 
It is necessary to point out that Fischer carbenes are much more reactive in this transformation than the corresponding chiral esters. Thus, the reaction of chiral trans-cinnamate 8 with trimethylsilyldiazomethane required higher temperature, longer reaction time, and occurred with a much poorer diastereoselectivity $(\mathrm{dr}=60 / 40)$.

The carbene function present in the initial [3+2] cycloadducts is capable to participate in subsequent transformations, letting us to enhance the complexity of the products. Thereby, the initial 1-metalla-1,3,5-hexatrienes resulting from the [3+2] cycloaddition of enynylcarbenes 9 with diazoalkanes or nitrones, participate in a benzannulation reaction with isocyanides, affording indazoles $\mathbf{1 0}$ or 2,3-dihydro-1,2-benzisoxazoles 12 respectively (Scheme 4). ${ }^{5}$ Both reactions proceed under mild conditions, in high yields and with complete regioselectivity.
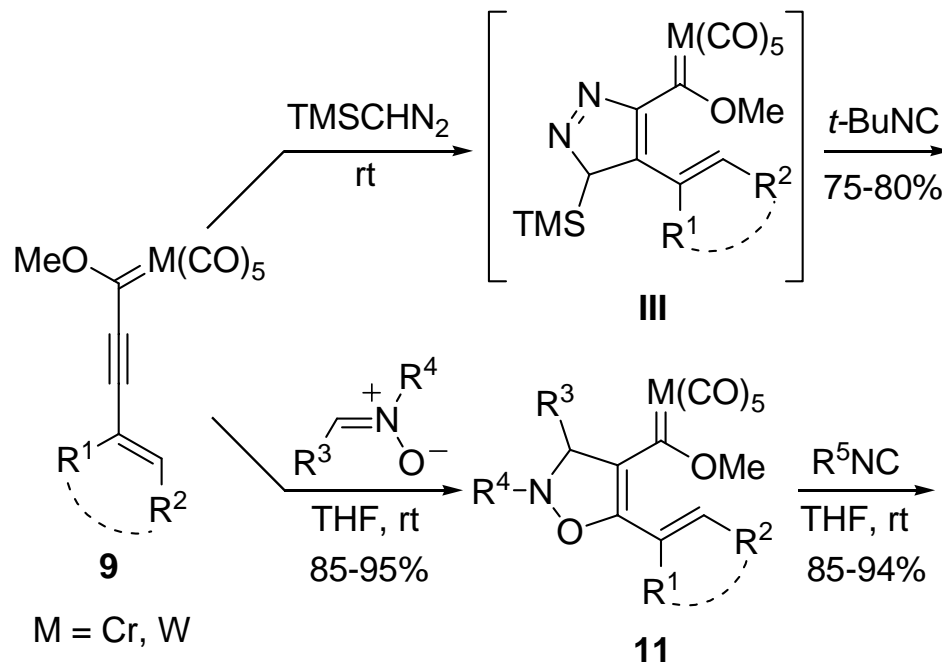

III<smiles></smiles>

10

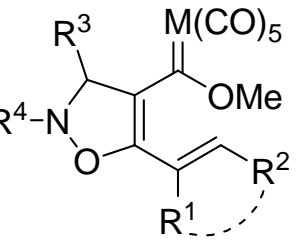

11

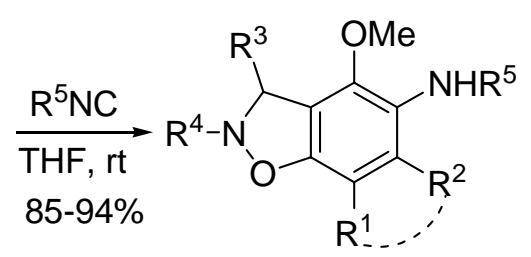

12

Scheme 4. Sequential [3+2] cycloaddition/insertion/cyclization reactions of carbenes 9.

\subsection{Reactivity of Fischer carbene complexes toward dienes and heterodynes}

2.3.1 [4+2] Cycloadditions. The Diels-Alder reaction is one of the most fascinating organic processes, particularly in terms of its synthetic potential.

It has been demonstrated that $\alpha, \beta$-unsaturated Fischer carbenes are excellent dienophile partners in this process, showing reaction rates and selectivities comparable to the Lewis acid catalysed reaction of the corresponding esters. An interesting example is represented in Scheme 5, where new spiro Fischer type carbenes $\mathbf{1 5}$ are obtained with almost complete diastereoselectivity through [4+2] cycloaddition of alkenyl carbene $\mathbf{1 3}$ and 2-amino-1,3butadienes $14 .^{6}$ 


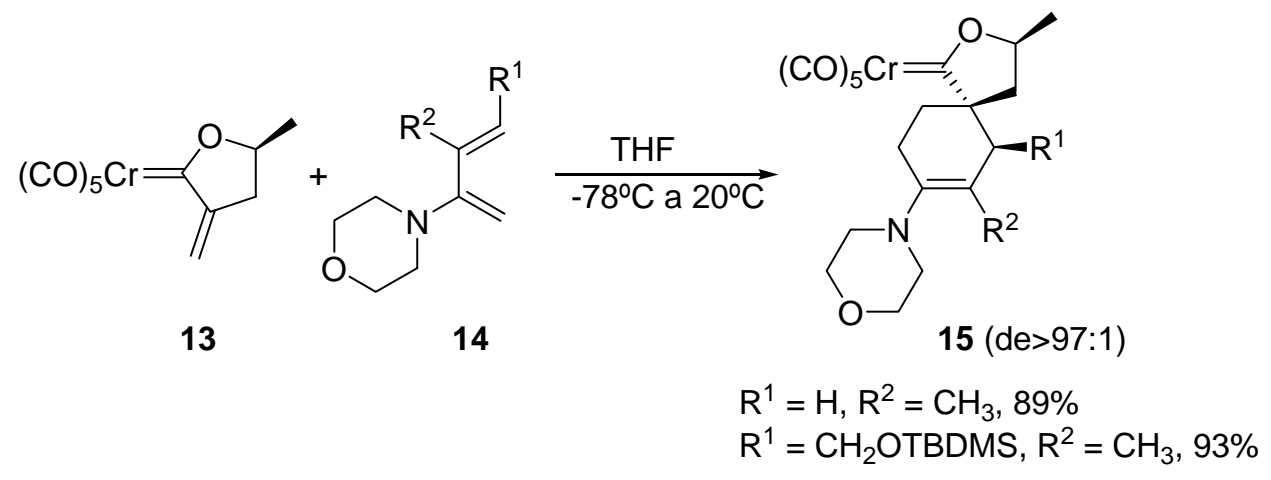

Scheme 5. [4+2] Cycloaddition of carbene complex 13 and 2-aminodienes.

In a similar way, tungsten alkynylcarbenes $\mathbf{1 7}$ react with 2-azadienes to afford the corresponding pyridone derivatives $\mathbf{1 8}$ as single diastereomers (Scheme 6). ${ }^{7}$ Moreover, the (phenylethynyl)carbene complex $\left(\mathrm{R}^{3}=\mathrm{Ph}\right)$ leads to a double cyclization process, generating 2azafluorene 19 in good yields. This transformation likely involves a selective electrocyclic ring closure of the [4+2] cycloadduct leading to a new metallacycle, which after a suprafacial $[1,5]-$ hydrogen shift and reductive elimination, gives the final 2-azafluorene.<smiles>[R]C=NC(=C[R])O[Na]</smiles>

16
17<smiles>[R]C1=C(C(=[W])OC)C([R])NC(=O)C1[R]</smiles>

18
$\underset{\left(\mathrm{R}^{3}=\mathrm{Ph}\right)}{\stackrel{\mathrm{THF}, 60^{\circ} \mathrm{C}}{\longrightarrow}}$ $62-76 \%$ $62-76 \%$

$\mathrm{R}^{1}=t$-Bu, Ph, 2-furyl

$\mathrm{R}^{2}=\mathrm{Me}, \mathrm{H}$ $\mathrm{R}^{3}=\mathrm{Ph}, \mathrm{SiMe}_{3}$<smiles>C=C(N=CC=[18O])OC(=O)C#CPc1ccccc1</smiles>

20<smiles>[R]C1NC(=O)C([R])C2=C1c1ccccc1[C@@H]2OC</smiles>

19 $\mathrm{R}^{1}=t-\mathrm{Bu}, \mathrm{Ph}$ $\mathrm{R}^{2}=\mathrm{Me}, \mathrm{H}$

Scheme 6. [4+2] Cycloaddition of alkynylcarbenes with 2-azadienes.

We have observed a higher reactivity of the alkynyl carbenes in comparison to the acetylenic ester analogues in this process. Thus, a solution of azadiene 20 and methyl phenylpropionate $\mathbf{2 1}$ was refluxed in toluene for seven days, resulting in the recovery of the starting materials. 
Recently, we have developed the first synthesis of group 6 enantiopure alkynylcarbene complexes derived from chiral alcohols, and carried out a [4+2] cycloaddition of these compounds with 1-azadienes, obtaining dihydropyridine complexes. ${ }^{8}$ The synthesis of the starting chiral alkynylcarbenes $\mathbf{2 3}$ is achieved in high yields by reaction of Fischer carbenes 22 with a chiral alkoxyacetylide in THF at $-40^{\circ} \mathrm{C}$, followed by trimethylsilyl triflate addition at $80^{\circ} \mathrm{C}$ (Scheme 7). The initially formed nonstabilized carbene $\mathbf{I V}$, observed by NMR at $-70^{\circ} \mathrm{C}$, undergoes rapid rearrangement to the more stable alkoxy carbene 23 by means of a [1,3]-metal shift.
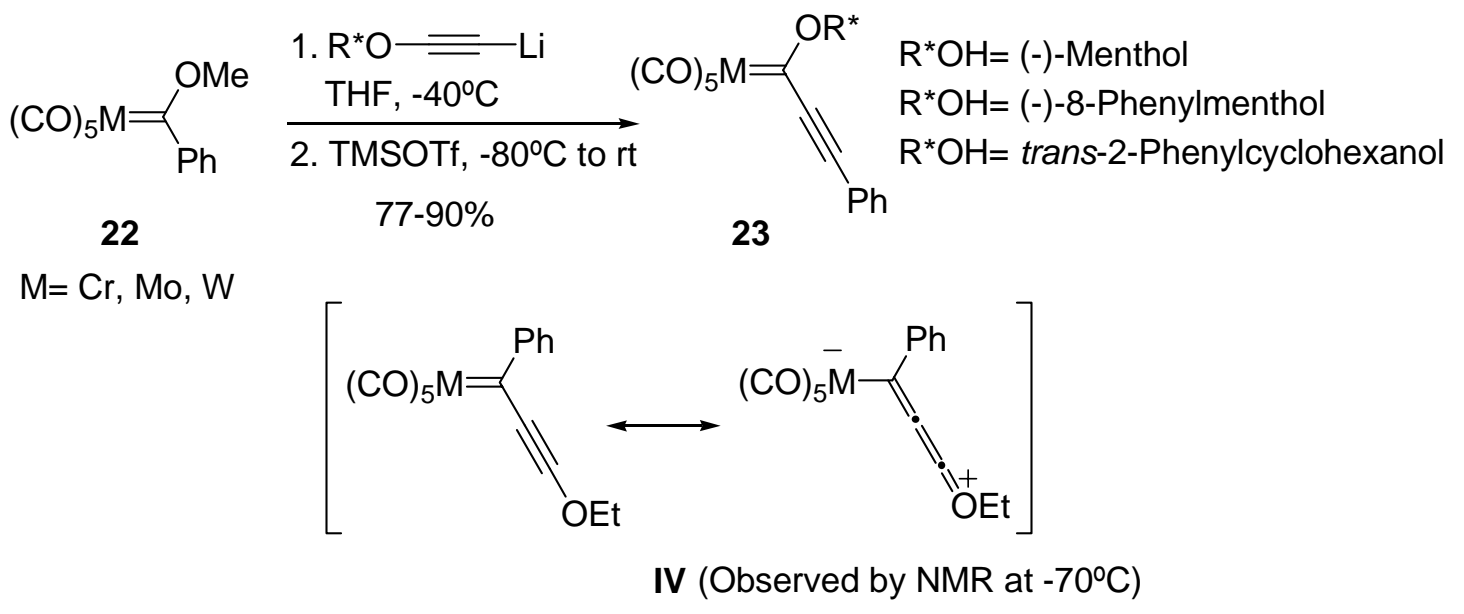

Scheme 7. Synthesis of novel enantiopure alkynylcarbene complexes.

In our laboratory, these novel chiral alkynyl(alkoxy)carbenes have been applied in the synthesis of 1,4-dihydropyridines through a [4+2] cycloaddition, as it is shown in Scheme $8 .^{8}$ Thereby, alkynylcarbene $\mathbf{2 4}$ reacted with 1-azadiene 25 in THF at room temperature furnishing the [4+2] cycloadduct 26 in 70\% yield regio- and diastereoselectively (observed by NMR analysis). Demetallation of the initial cycloadduct and removal of the chiral auxiliary by treatment with a copper (I) complex in wet $\mathrm{CH}_{2} \mathrm{Cl}_{2}$ yielded aldehyde 27 as a single enantiomer.

A feasible mechanism for this transformation would involve: i) conjugated addition of the nitrogen atom of the azadiene to the more accessible face of the alkyne moiety in the more stable configuration of 24 (considering a likely $\pi$-stacking effect) generating intermediate $\mathbf{V}$, with central and axial chirality; and ii) final cyclization through the $R e$ face of the $\mathrm{C}=\mathrm{C}$ bond. 


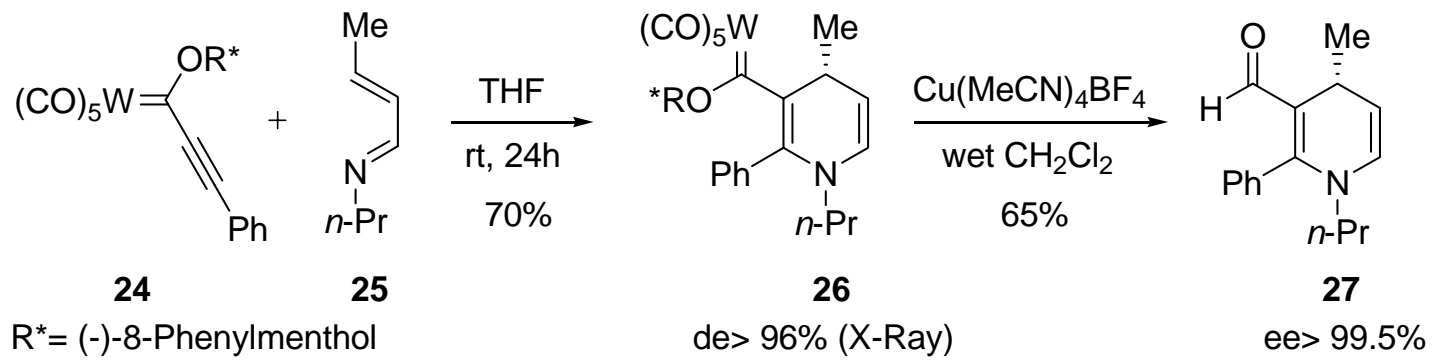

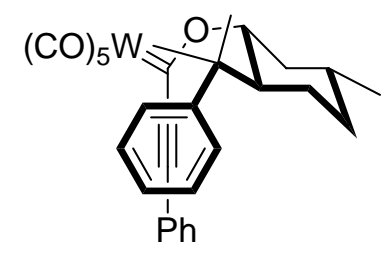

24

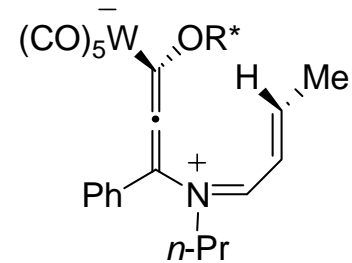

$\mathrm{V}$

Scheme 8. [4+2] Cycloaddition of chiral alkynylcarbene complexes and 1-azadienes.

2.3.2 [4+3] Cycloadditions.[4+3] Heterocyclizations have been accomplished in our group starting from 4-amino-1-azadiene derivatives. As it is shown in Scheme 9, chromium and tungsten alkenylcarbenes 29 react with 4-amino-1-aza-1,3-butadienes in THF at low temperature $\left(-80\right.$ to $\left.-40^{\circ} \mathrm{C}\right)$ affording, after treatment with silica gel, azepines $\mathbf{3 0}$ as single diastereoisomers. ${ }^{9}$

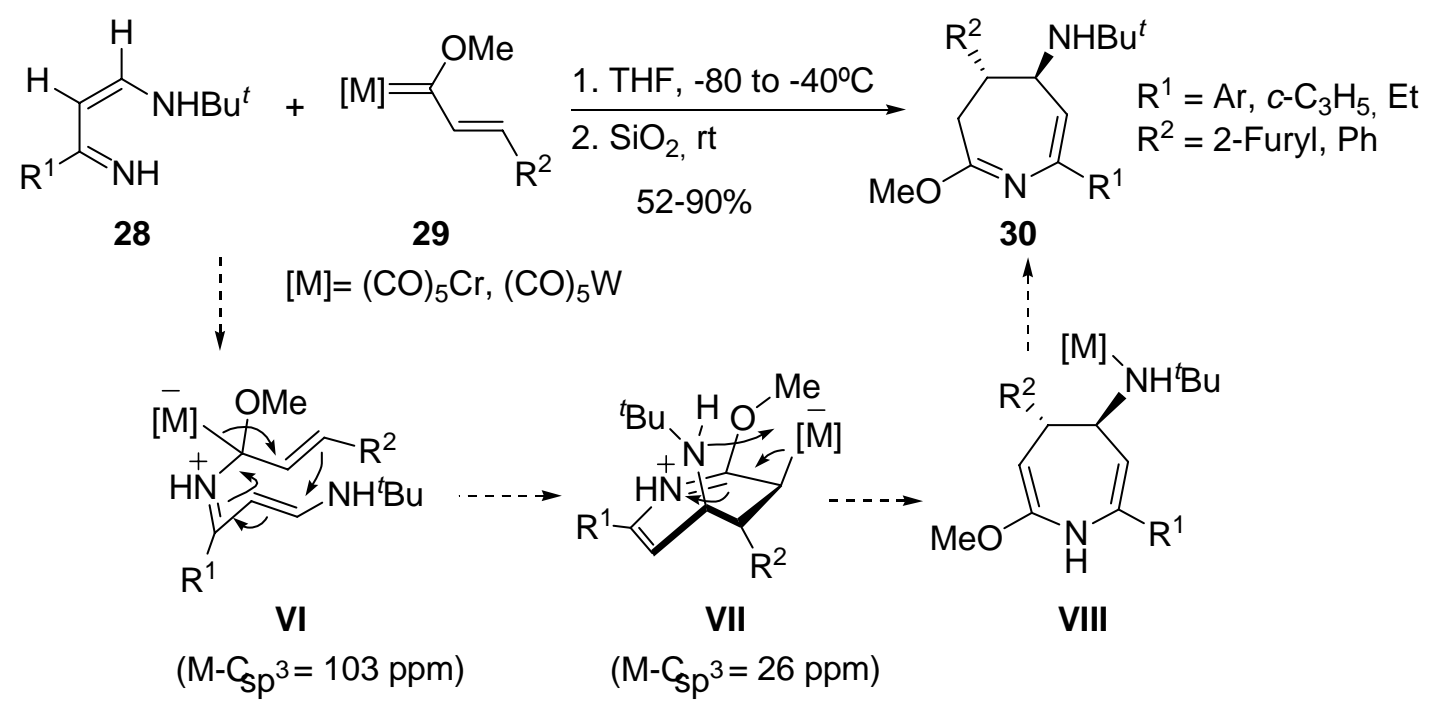

Scheme 9. [4+3] Annulation of 4-amino-1-azadienes with Fischer carbene complexes.

A detailed NMR study of the reaction allowed us to propose a suitable mechanism (Scheme 9). A nucleophilic attack of the unsubstituted nitrogen of azadiene at the carbenic carbon could be the first step of the reaction, leading to the formation of zwitterion VI, stabilized in a chairlike conformation. Secondly, a $[1,2]-\mathrm{Cr}(\mathrm{CO})_{5}$ shift would induce the diastereoselective 
cyclization to give intermediate VII, which after elimination of the metallic fragment and metal coordination to the nitrogen would form VIII. Finally, the decomplexation of the metallic fragment and tautomerization in the presence of silica gel would lead to azepines $\mathbf{3 0 .}$

A chiral version of this transformation was accomplished using chiral, nonracemic carbene complexes 32 (derived from (-)-menthol) and oximes 31 (Scheme 10). ${ }^{9}$ This reaction requires one equivalent of a simple carbene complex, which acts as a reducing agent to remove the oxygen of the oxime functionality at some point during the process. Significantly, the major diastereoisomers were found to crystallize from methanol, allowing the isolation of both azepines $\mathbf{3 3}$ and $\mathbf{3 4}$ in a diastereomerically pure form.

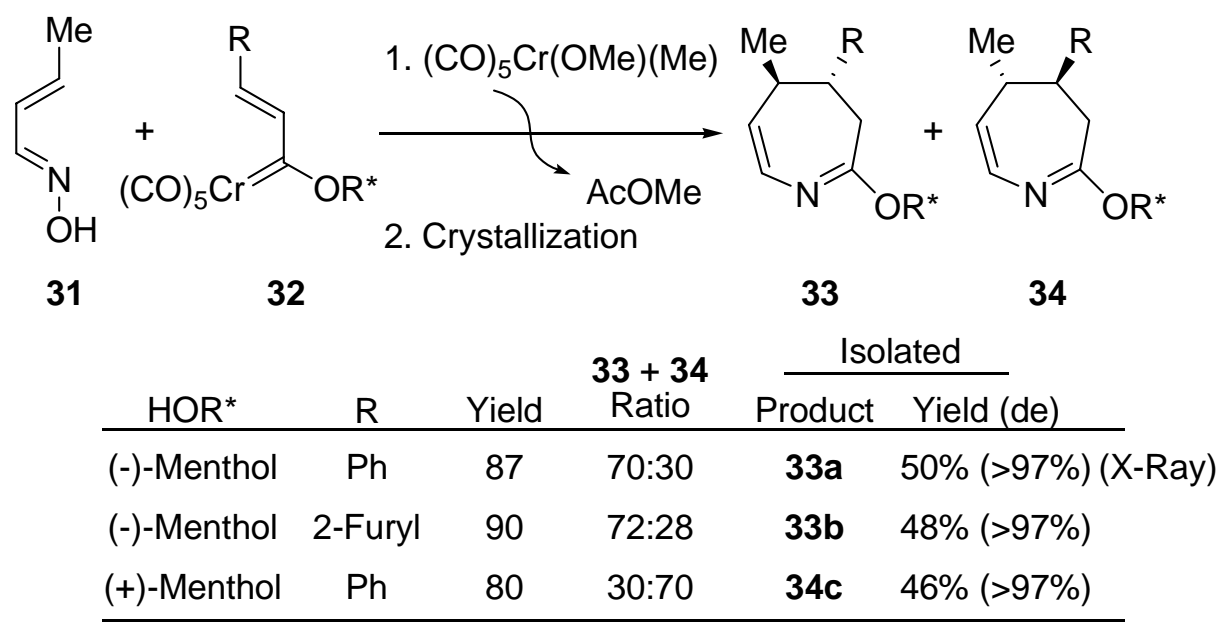

Scheme 10. [4+3] Cycloaddition of enantiopure carbene complexes and oximes.

Hydrolysis of chiral azepine 33a with $3 \mathrm{M} \mathrm{HCl}$ in THF led to formyl ester 35 in 93\% yield, accompanied by a small amount of azepinone 36 ( $<5 \%$ yield). ${ }^{9}$ The entire protocol formally represents the enantioselective Michael addition of ester homoenolates to $\alpha, \beta$-unsaturated aldehydes, in which two chiral centers are created. Finally, the chiral auxiliary was efficiently removed by reduction of 35 with $\mathrm{LiAlH}_{4}$ at room temperature, obtaining chiral diol 37 in $95 \%$ yield. 


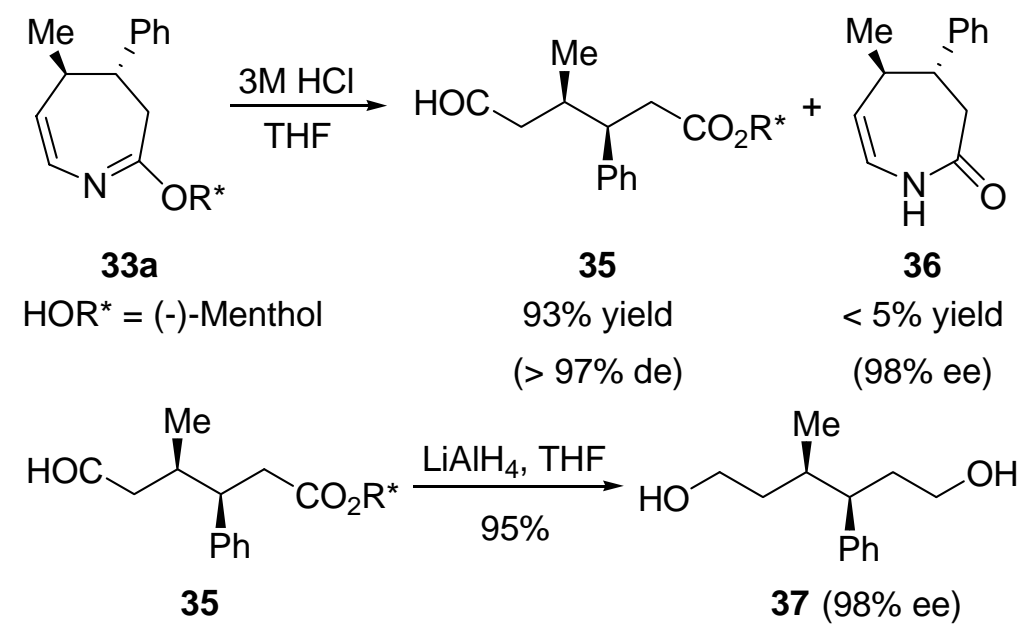

Scheme 11. Further elaboration of azepine 33a.

Chromium alkynylcarbenes also participate in this type of reaction. Thus, 2-azepinones $\mathbf{4 0}$ were isolated in high yields after stirring alkynylcarbenes 38 with 1-azadienes 39 at room temperature, in hexane or THF as a solvent. ${ }^{10}$ This reaction, a formal [4+3] cycloaddition, is thought to commence by an initial nucleophilic addition of the imine nitrogen of the azadiene on the carbenic carbon, originating the zwitterionic species IX. Finally, a [1,2]-Cr(CO) $)_{5}$ shift would induce the cyclization of IX to generate the obtained product 40. Remarkably, the structure of $\mathbf{4 0}$ was confirmed by X-ray crystal analysis, demonstrating then the shift of the pentacarbonylchromium moiety during this transformation.

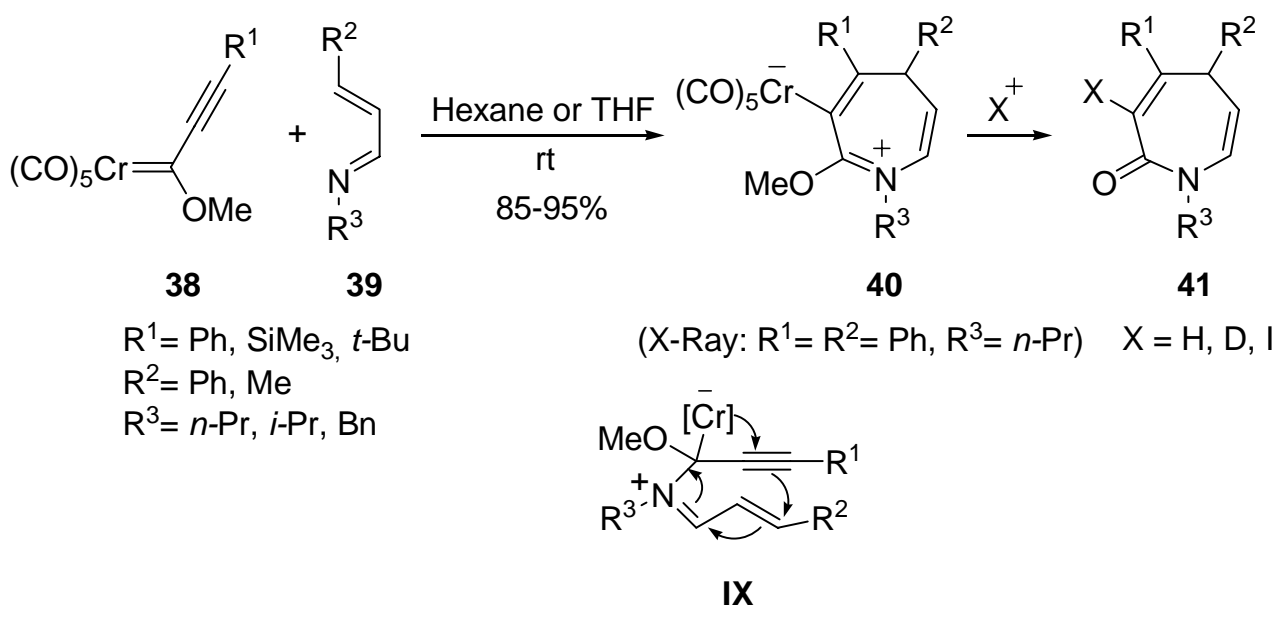

Scheme 12. [4+3] Cycloaddition of alkynyl Fischer carbenes and 1-azadienes. 


\subsection{Reactivity of Fischer carbene complexes toward enolates}

In our research group we have carried out a deep study on the addition of different types of enolates to Fischer carbenes. An enantioselective approach has been also considered, placing the chirality on the Fischer carbene complex or on the enolate, as it will be commented next.

2.4.1 Addition of enolates to chiral alkenyl carbene complexes. The use of alkenyl carbenes derived from (-)-8-phenylmentol with lithium ketone enolates, let us to obtain highly functionalized adducts as single diastereoisomers in most cases. ${ }^{11}$
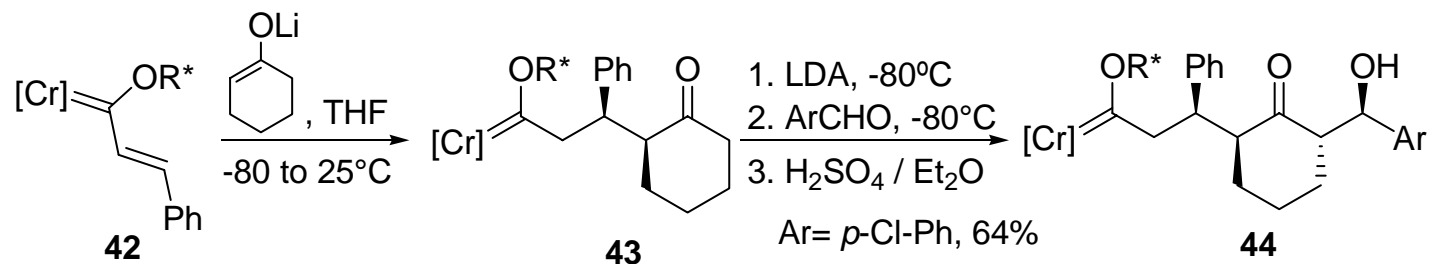

43

$\mathrm{Ar}=p-\mathrm{Cl}-\mathrm{Ph}, 64 \%$

44

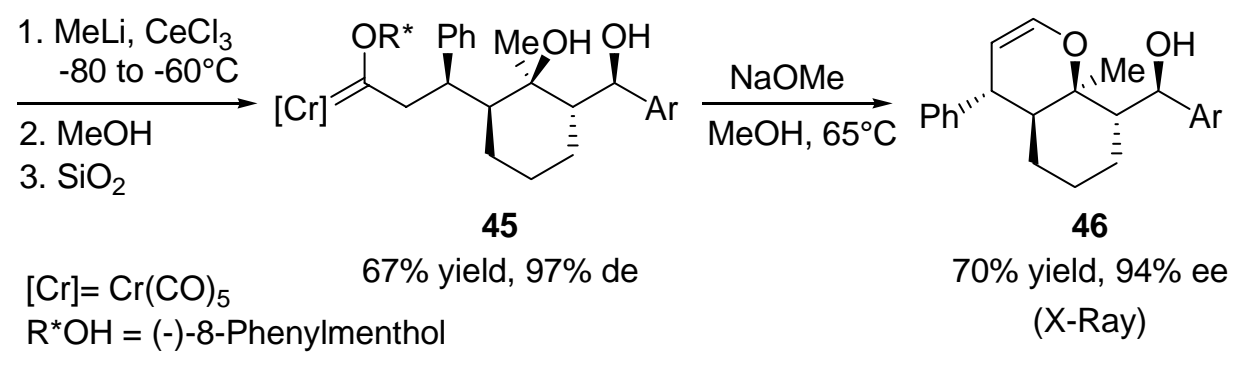

Scheme 13. Michael addition of enolates to chiral alkenyl Fischer carbene complexes.

The key step for the preparation of bicyclic enol ether $\mathbf{4 6}$ shown in Scheme 13, with five contiguous stereogenic centers, was the enantioselective addition of cyclohexanone enolate to the enantiopure Fischer alkenyl carbene 42. ${ }^{11 a}$ The configuration of all new stereocenters was unequivocally established by X-ray analysis of the final enol ether.

2.4.2 Addition of chiral enolates to alkenyl carbene complexes. Taking into account the results commented above, we designed a synthesis of eight-membered carbocycles in an enantioselective manner by addition of chiral enolates to alkenyl Fischer carbenes. ${ }^{12}$ This sequence is depicted in Scheme 14. Thus, the enolate generated from enantiopure silyl enolether 47, easily obtained from 2-cyclohexenone, reacted with chromium alkenyl carbenes at low temperature to produce the Michael addition product 48. Secondly, addition of allyllithium gave rise to the new cyclic carbene $\mathbf{4 9}$, which upon heating at $90^{\circ} \mathrm{C}$ in THF in a sealed tube generated tetracyclic compound 50, arising from the cyclopropanation of the double bond. Remarkably, each of these steps occurred with complete diastereoselectivity. Finally, treatment of the cyclopropyl derivative $\mathbf{5 0}$ with hydrocloric acid in acetone afforded the eight-membered hemiketal $\mathbf{5 1}$ as a single diastereoisomer $(>98 \%$ de), whose structure was unequivocally determined by an X-ray structure analysis. 


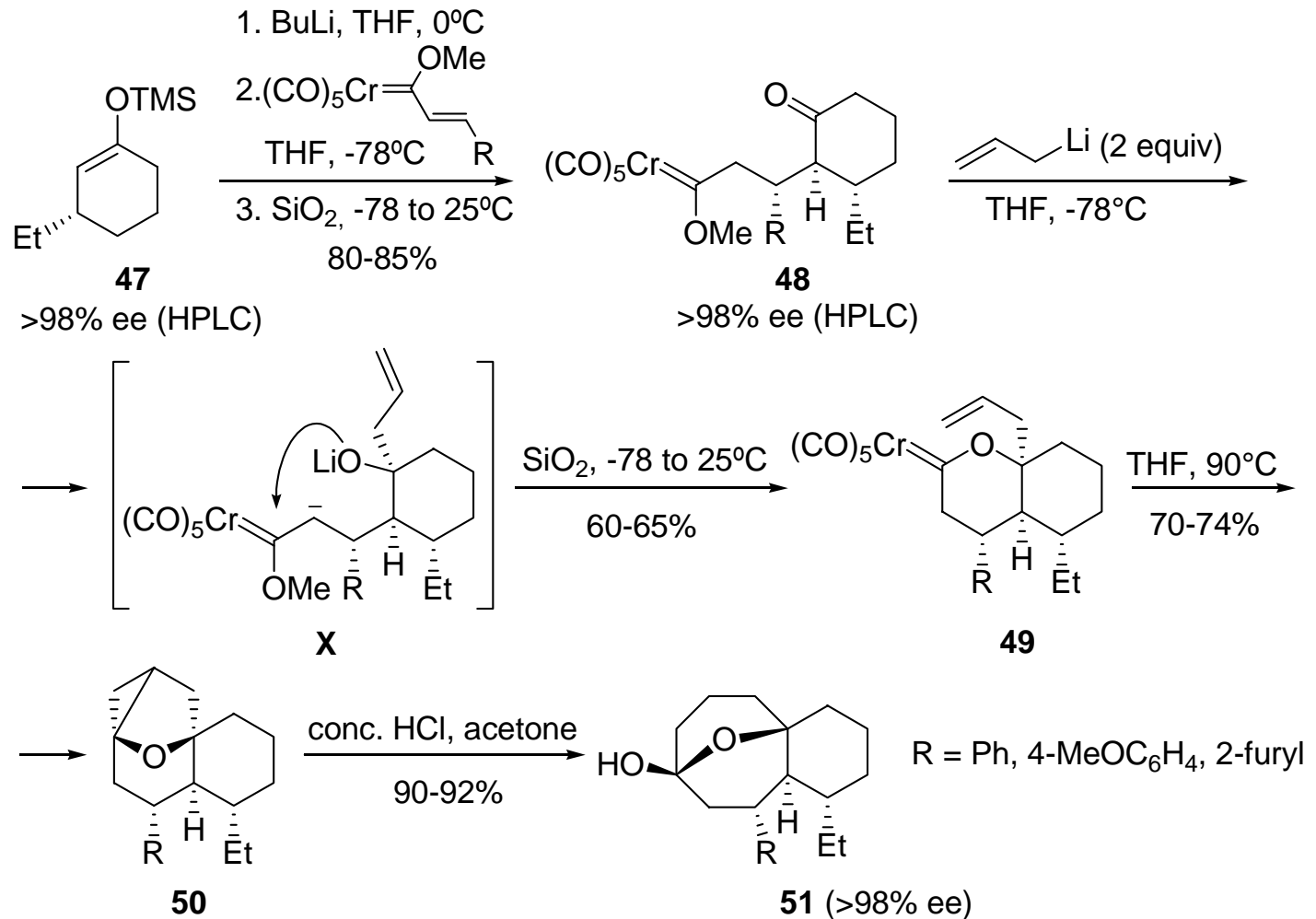

Scheme 14. Michael addition of a chiral enolate to alkenyl carbenes.

Interestingly, the synthesis of the eight-membered hemiketals $\mathbf{5 1}$ can be carried out in a one-pot sequence without the isolation of any intermediate, as it is shown in Scheme 15. As a result, this strategy was much more efficient than the multistep process, leading to an improvement of the yield from $37 \%$ to $75-80 \%$.

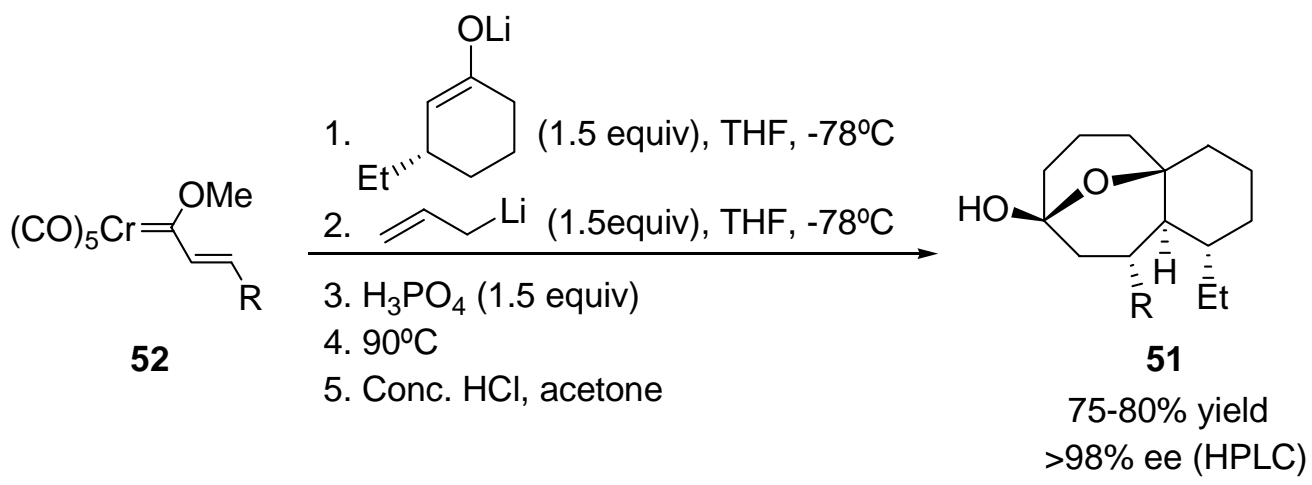

Scheme 15. One-pot synthesis of 51.

2.4.3 Cycloadditions with methyl ketone enolates. The addition of methyl ketone enolates to Fischer carbene complexes has turned out to be a very useful strategy for the diastereoselective 
synthesis of five-membered carbocycles, through a [3+2] cyclization reaction. Thus, the treatment of alkenyl carbene complexes 53 with methyl ketone enolates 54, in THF at temperatures from $0^{\circ} \mathrm{C}$ to room temperature led to cyclopentenol derivatives 55 in high yields, after hydrolysis and purification by flash chromatography on deactivated silica gel (Scheme 16). ${ }^{13}$ Addition of $N, N, N^{\prime}, N^{\prime}, N^{\prime}$ ',-pentamethyldiethylenetriamine (PMDTA) improved the diastereoselectivity up to $95 \%$. On the contrary, when the reaction was carried out using diethyl ether as a solvent, a different diastereoisomer (56) was obtained in good yields and with almost complete diastereoselectivity.

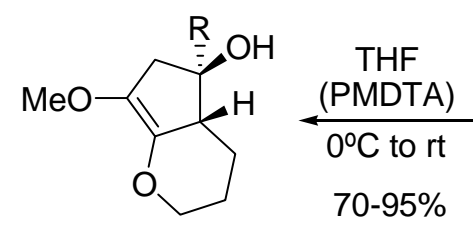

55

90-95\% de

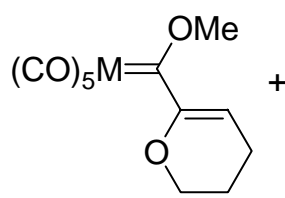

53

$\mathrm{M}=\mathrm{Cr}, \mathrm{W}$

$\mathrm{R}=$ alkyl, aryl, alkenyl, alkynyl

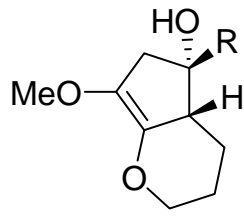

56

$>95 \%$ de

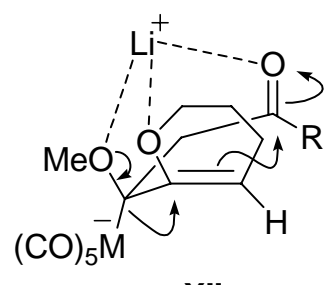

XI'

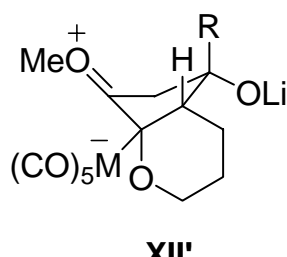

XII'

Scheme 16. [3+2] Cycloaddition of alkenyl carbenes and methyl ketone enolates.

The first step in this reaction is assumed to be a 1,2-addition of lithium enolates 54 to the carbenic carbon in 53, to form intermediates XI or XI'. The 1,2-migration of the metallic fragment would then induce a cyclization, leading to bicyclic intermediates XII or XII'. Finally, a further elimination of the metal moiety and hydrolysis furnish the cyclopentenol derivatives 55 or 56, respectively. When the reaction is carried out in $\mathrm{Et}_{2} \mathrm{O}$, a less coordinating solvent than THF, coordination of the lithium atom to three oxygen atoms favours a transition structure with a geometric disposition of that in XI', explaining then the formation of diastereomer $\mathbf{5 6 .}$

The reactivity of dienylcarbenes toward methyl ketone enolates has been also studied, and constitutes a diastereoselective route to seven-membered carbocycles under very mild conditions. Thereby, treatment of tungsten dienylcarbenes 57 with lithium enolates 54 in diethyl ether at temperatures from $0^{\circ} \mathrm{C}$ to room temperature led to cycloheptadienol derivatives 58 in good yields, after hydrolysis and purification by flash chromatography on deactivated silica gel (Scheme 17). ${ }^{14}$ This process occurs with complete diastereoselectivity, and represents the first example of a formal [5+2] carbocyclization reaction of Fischer-type carbene complexes.

The reaction is probably initiated by a 1,2-addition of the enolate to the carbene complex to form intermediate XIII, which would then evolve by intramolecular addition of the 5-position of 
the $\sigma$-dienyl metal group to the carbonylic carbon atom, induced by a 1,2-migration of the metallic fragment.

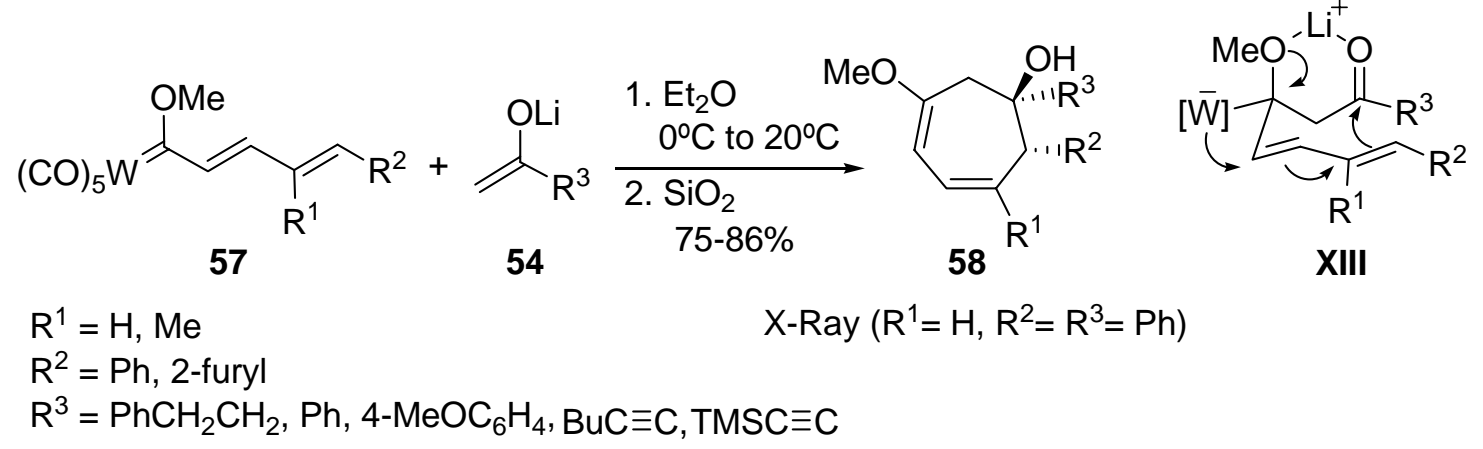

Scheme 17. [5+2] cycloaddition of dienylcarbenes and methyl ketone enolates.

2.4.4 Multicomponent couplings of lithium enolates and allylmagnesium bromide. As it has been described in the former section, the 1,2-addition reaction of lithium enolates to alkenyl Fischer carbene complexes produces anionic pentacarbonylmetallate species, which evolve further to give different organic products depending on the reaction conditions and the structural features of the reaction partners. On the other hand, interesting synthetic sequences have been recently developed in our group for the one-pot preparation of cyclopentanols and cyclohexanols, using simple Fischer carbenes 59 as substrates for the enolate addition (Scheme 18). ${ }^{15}$ Thus, the consecutive addition of $\beta$-substituted lithium enolates and allylmagnesium bromide to simple carbene complexes 59, under the reaction conditions indicated in Scheme 18, led diastereoselectively to pentasubstituted cyclopentanols 60 or 61 , depending on the type of enolate used, after final hydrolysis.

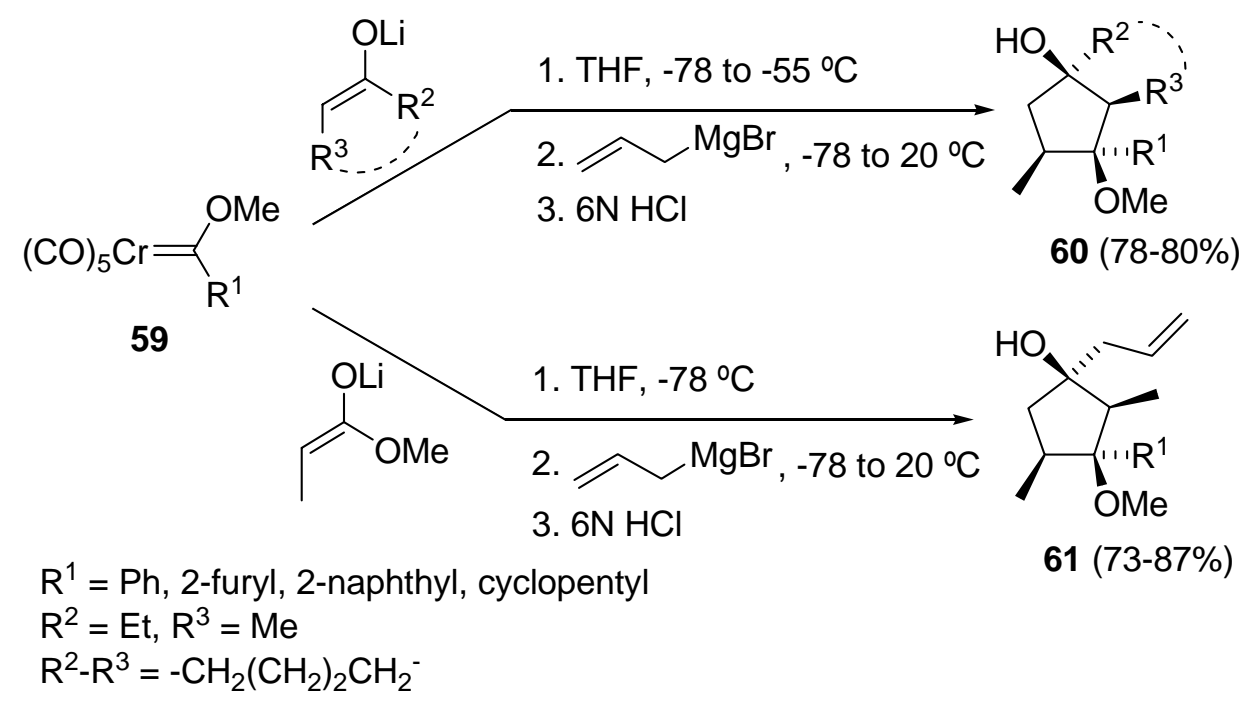

Scheme 18. One-pot, three-component synthesis of polysubstituted cyclopentanols. 
Additionally, the consecutive addition of $\beta$-unsubstituted lithium enolates and allylmagnesium bromide to simple Fischer carbenes 59 gave rise diastereoselectively to tetrasubstituted cyclohexane-1,4-diols 62 or 63, depending on the type of enolate used (Scheme 19). ${ }^{15}$ The ring skeleton of cyclopentanols 60, 61 combines the carbene ligand, the enolate framework, and one or two allyl units, whereas that of cyclohexadienols 62, 63 also incorporates a carbonyl ligand.

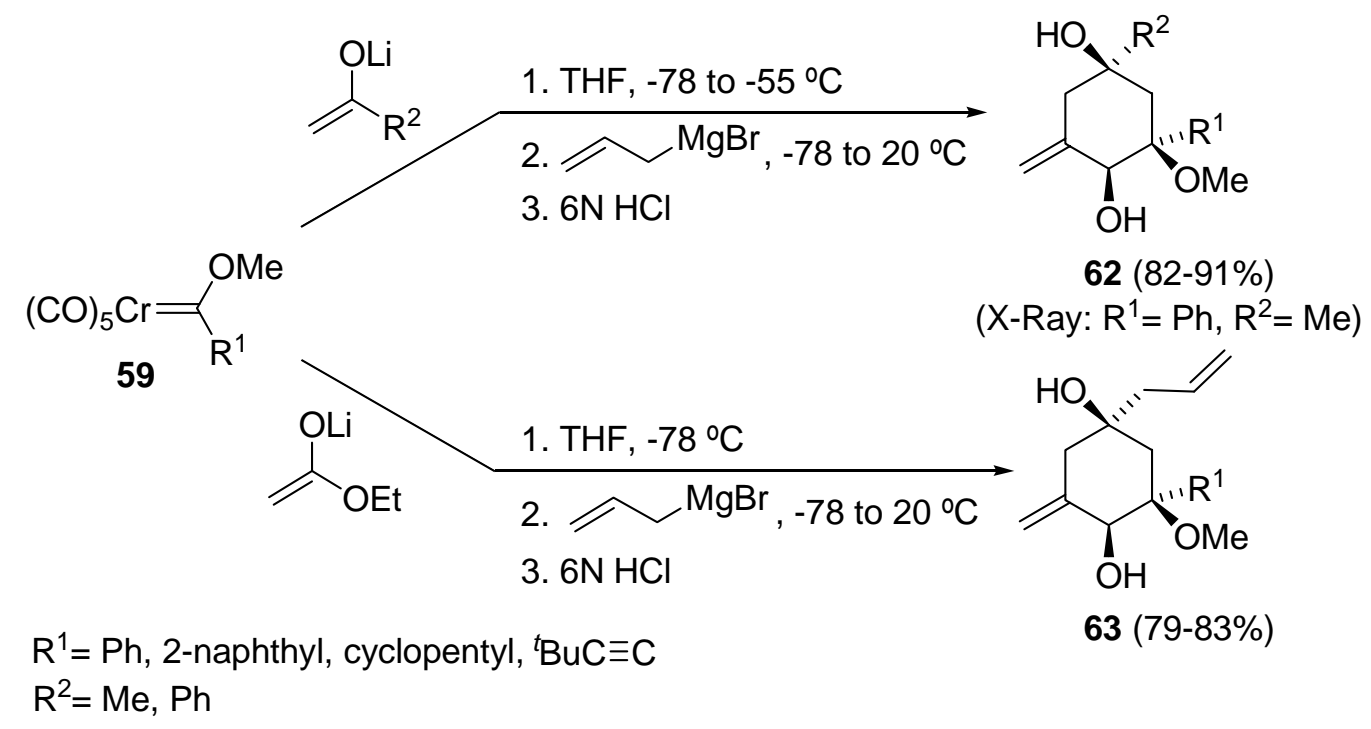

Scheme 19. One-pot, four component synthesis of polysubstituted cyclohexadienols.

A feasible mechanism to account the formation of these five- and six-memebered ring products is depicted in Scheme 20. The first two steps would be common for both products, consisting on an initial 1,2-addition of the lithium enolate to the carbenic carbon of complexes 67 generating intermediate XIV, followed by addition of allylmagnesium bromide to the carbonyl group leading to $\mathbf{X V}$. Complexes $\mathbf{X V}$ with a substituent at $\mathrm{C}_{2}\left(\mathrm{R}^{3} \neq \mathrm{H}\right)$ undergo an intramolecular carbometalation reaction giving the chromate derivatives XVI, which are then protonated to furnish cyclopentanols $\mathbf{6 0}$. On the contrary, complexes $\mathbf{X V}$ without a substituent at $\mathrm{C} 2\left(\mathrm{R}^{3}=\mathrm{H}\right)$ undergo CO migratory insertion generating tetracarbonylchromate species XVII, which then experience an intramolecular insertion of the carbene carbon atom into the secondary vinylic $\mathrm{C}-\mathrm{H}$ bond forming intermediate XVIII. A final protonation through XIX leads to cyclohexanediols 62. 


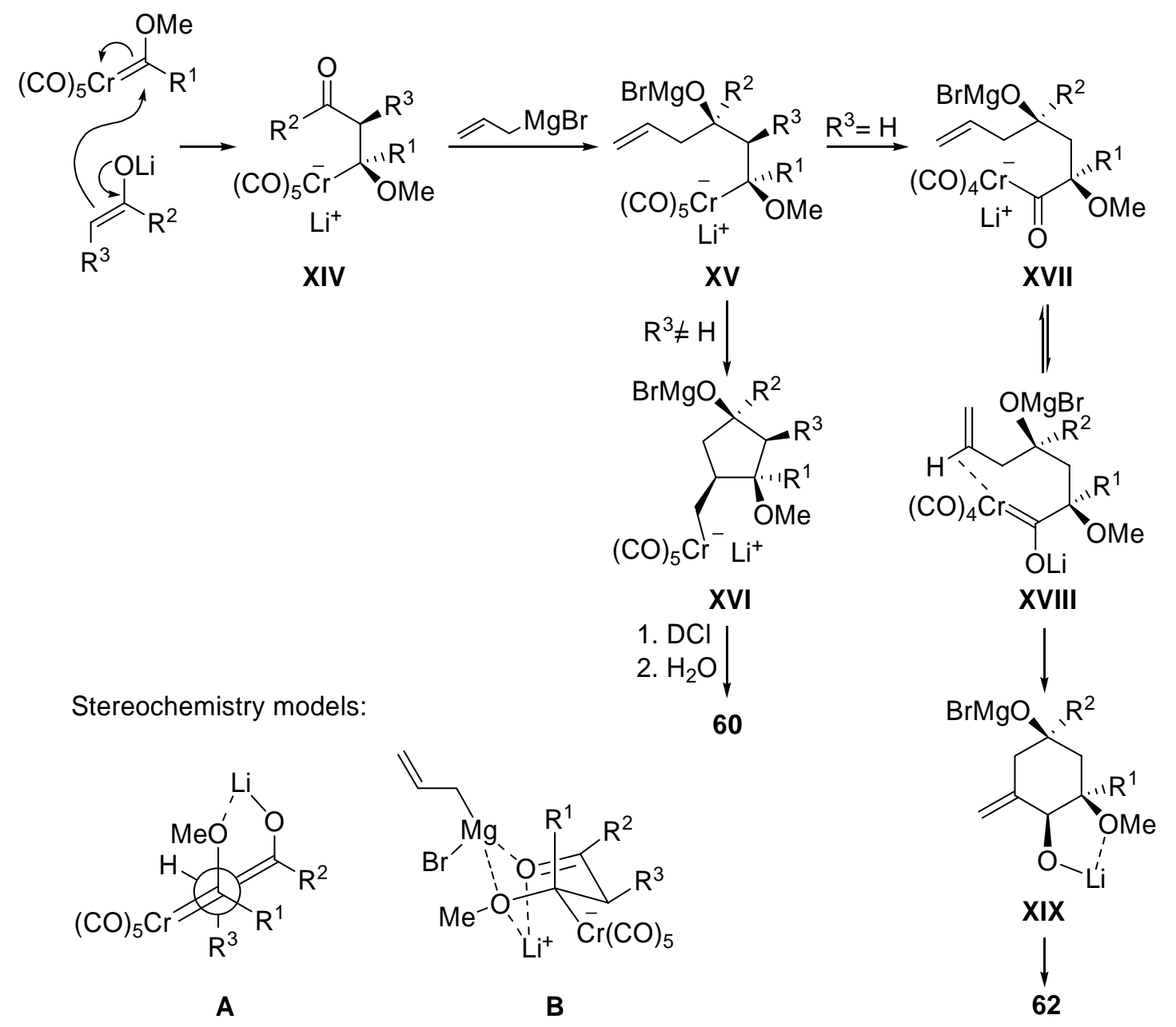

Scheme 20. Proposed mechanism for the formation of $\mathbf{6 8}$ and $\mathbf{7 0 .}$

A coordination of the lithium center to the oxygen atom of the methoxy group would account for the diastereoselectivity in the first reaction step (Scheme 20, topology A). The diastereoisomer formed in the second reaction step can be rationalized by a chelation-controlled transition state in which allylmagnesium bromide adds to the less-hindered face of the carbonyl group, as it is indicated in $\mathbf{B}$.

\subsection{Reactivity of Fischer carbene complexes toward pentafulvenes}

The cross-conjugated pentafulvene system constitutes a very attractive building block for the preparation of cyclopentanoids, considering its synthetic equivalence to the short-lived cyclopentadienone unit. Therefore, we became interested in the reactivity of Fischer carbenes toward these pentafulvene systems and its application to the synthesis of polycycles through different cyclization reactions. 

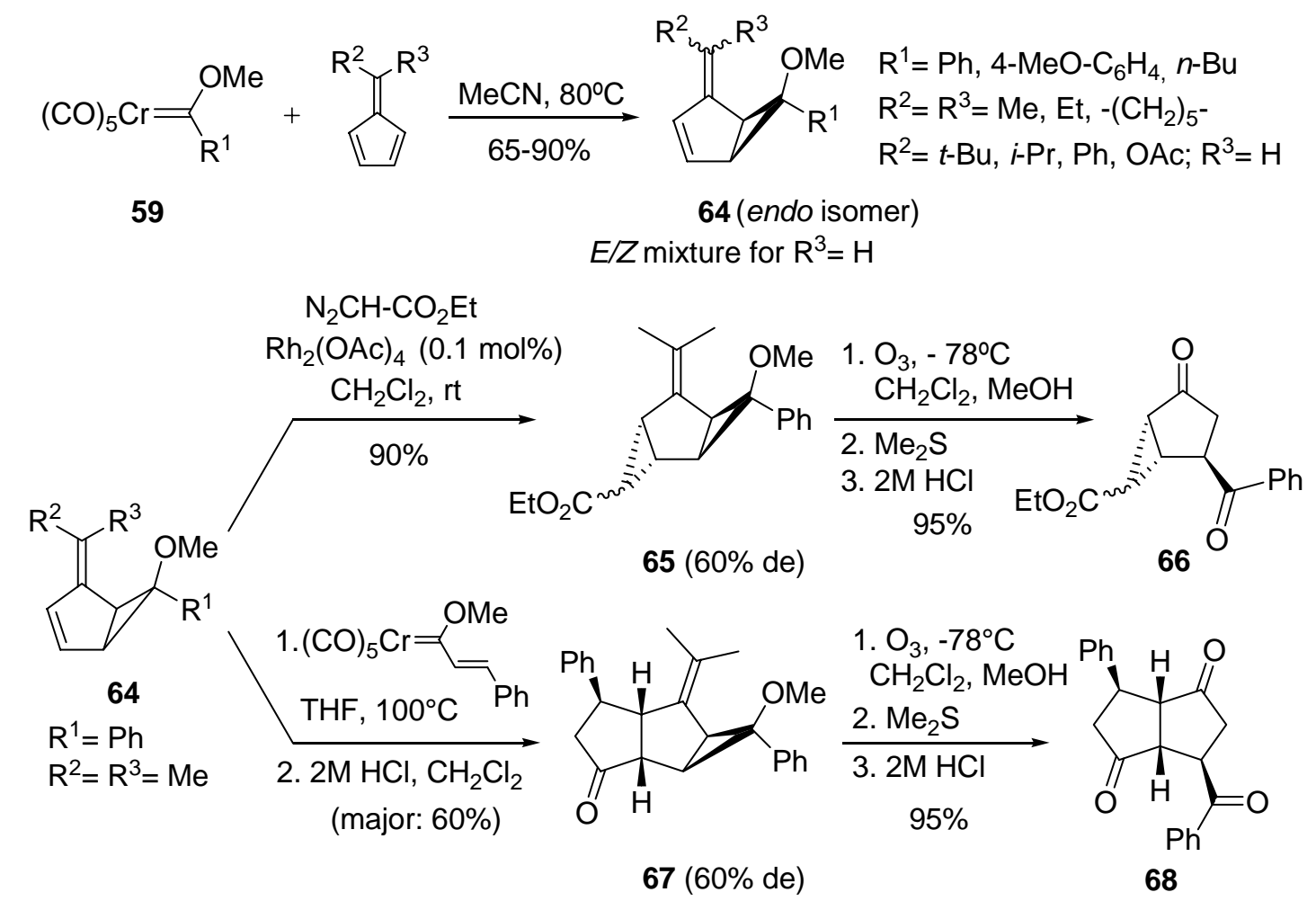

Scheme 21. Cyclopropanation/cyclopentannulation of fulvenes with Fischer carbenes.

Simple chromium Fischer carbenes 59 toward fulvenes showed to react with fulvenes in acetonitrile at $80^{\circ} \mathrm{C}$, forming the cyclopropanation products 64 with complete endo-selectivity (Scheme 21). ${ }^{16}$ When monosubstituted fulvenes were used, homofulvenes $\mathbf{6 4}$ were obtained as an $E / Z$ mixture, except for the compound derived from $t$-butylfulvene, isolated as a single $E$-isomer. The homofulvene derived from 6,6-dimethylfulvene undergoes a second cyclopropanation with two different reagents: i) reaction with ethyl diazoacetate $/ \mathrm{Rh}_{2}(\mathrm{OAc})_{4}$ produced the tricyclic compound 65 as a 4:1 mixture of epimers, which after final ozonolysis and acid hydrolysis led to the elaborated cyclopentanone 66; ii) reaction with the chromium alkenyl carbene indicated formed the cyclopentannulation adduct $\mathbf{6 7}$ as the major diastereoisomer $(60 \% \mathrm{de})$ after heating the mixture in $\mathrm{THF}$ at $100^{\circ} \mathrm{C}$ (in sealed tube) and subsequent acid hydrolysis. Further ozonolysis and hydrolysis of the major diastereoisomer led to the functionalized diquinane $\mathbf{6 8}$ in $95 \%$ yield. The overall processes illustrate the use of 6,6-dimethylfulvene as a substitute for the elusive cyclopentadienone.

The cyclopropanation reaction was successfully extended for the first time to Fischer alkynyl carbene complexes, as it is indicated in Scheme 22. ${ }^{16}$ Thus, tungsten pentacarbonyl [phenylethynyl(methoxy)]carbene complexes 17 reacted with various 6,6-dialkyl and 6-aryl fulvenes at $60^{\circ} \mathrm{C}$ in hexane or THF respectively, to form the cyclopropanation products 69 in 65 $73 \%$ yield. In contrast to simple Fischer carbenes, the alkynyl complexes led to the exo 
diastereoisomer preferentially or exclusively, and the homofulvenes derived from 6-arylfulvenes were formed only as the E-isomer.

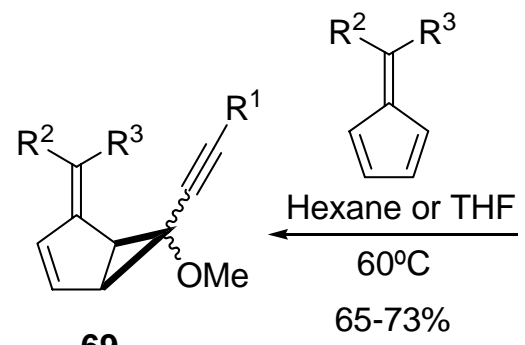

69

exo: 50 to $>98 \%$ de

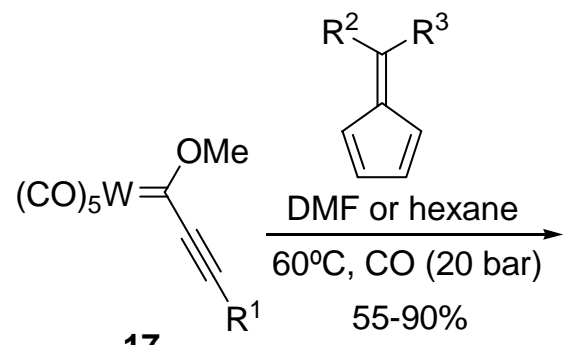

17

$\mathrm{R}^{1}=\mathrm{Ph}, 1$-cyclohexenyl

$\mathrm{R}^{2}=\mathrm{R}^{3}=\mathrm{Me},-\left(\mathrm{CH}_{2}\right)_{5^{-}}$

$\mathrm{R}^{2}=i-\mathrm{Pr}, t-\mathrm{Bu}, \mathrm{Ph}, \mathrm{OAc} ; \mathrm{R}^{3}=\mathrm{H}$

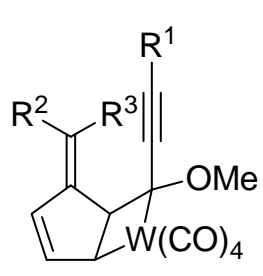

$\mathrm{XX}$

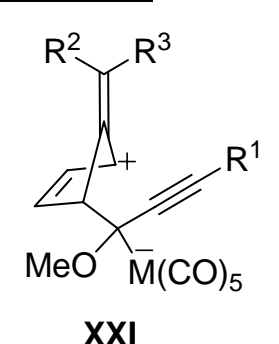

XXI

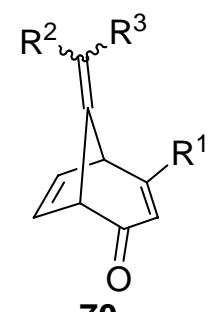

70

$E / Z$ mixture for $\mathrm{R}^{3}=\mathrm{H}$

Scheme 22. [2+1] and [4+3] cyclizations of alkynyl carbene complexes and fulvenes.

As the formation of the metalacyclobutane $\mathbf{X X}$, the first intermediate in the cyclopropanation reaction, requires the previous dissociation of a $\mathrm{CO}$ molecule from the carbene complex, we anticipated that carrying out the reaction under pressure of carbon monoxide the cyclopropanation would be inhibited, leading to a different reactivity. Thus, the reaction of alkynylcarbene complexes 17 with different fulvenes in the same conditions as above, but under $\mathrm{CO}$ pressure (20 bar) furnished the [4+3] cycloadducts $\mathbf{7 0}$ in moderate to high yields, allowing the quantitative recovery of $\mathrm{W}(\mathrm{CO})_{6}$. The formation of these bicyclo[3.2.1] octadien-2-ones 70 can be explained by a 1,2-addition of fulvene to the carbenic carbon of the Fischer carbene to generate intermediate $\mathbf{X X I}$, and a regioselective cyclization promoted by 1,2-[W(CO) 5 shift.

On the contrary, Fischer alkenyl carbene complexes showed a completely different reactivity pattern consisting on a [6+3] carbocyclization, previously unknown for Fischer carbenes and very uncommon in fulvenes. Thus, the reaction of chromium alkenyl alkoxycarbene complexes with 6-acetoxyfulvene in acetonitrile at $80^{\circ} \mathrm{C}$ generated the substituted indenes 72 as a mixture of tautomers (Scheme 23). ${ }^{17}$ Remarkably, 6-acetoxyfulvene reacted with alkenyl aminocarbene complexes as well, despite their well-known considerably less reactivity in nucleophilic additions. Moreover, the reaction of alkoxyalkenyl carbenes with alkyl and alkenyl fulvenes in acetonitrile at $80^{\circ} \mathrm{C}$ furnished also the [6+3] cycloadducts, which after acid 
hydrolysis were transformed into indanones 73 in good overall yields. Species of the type XXII and XXIII are thought to participate in these annulation reactions.

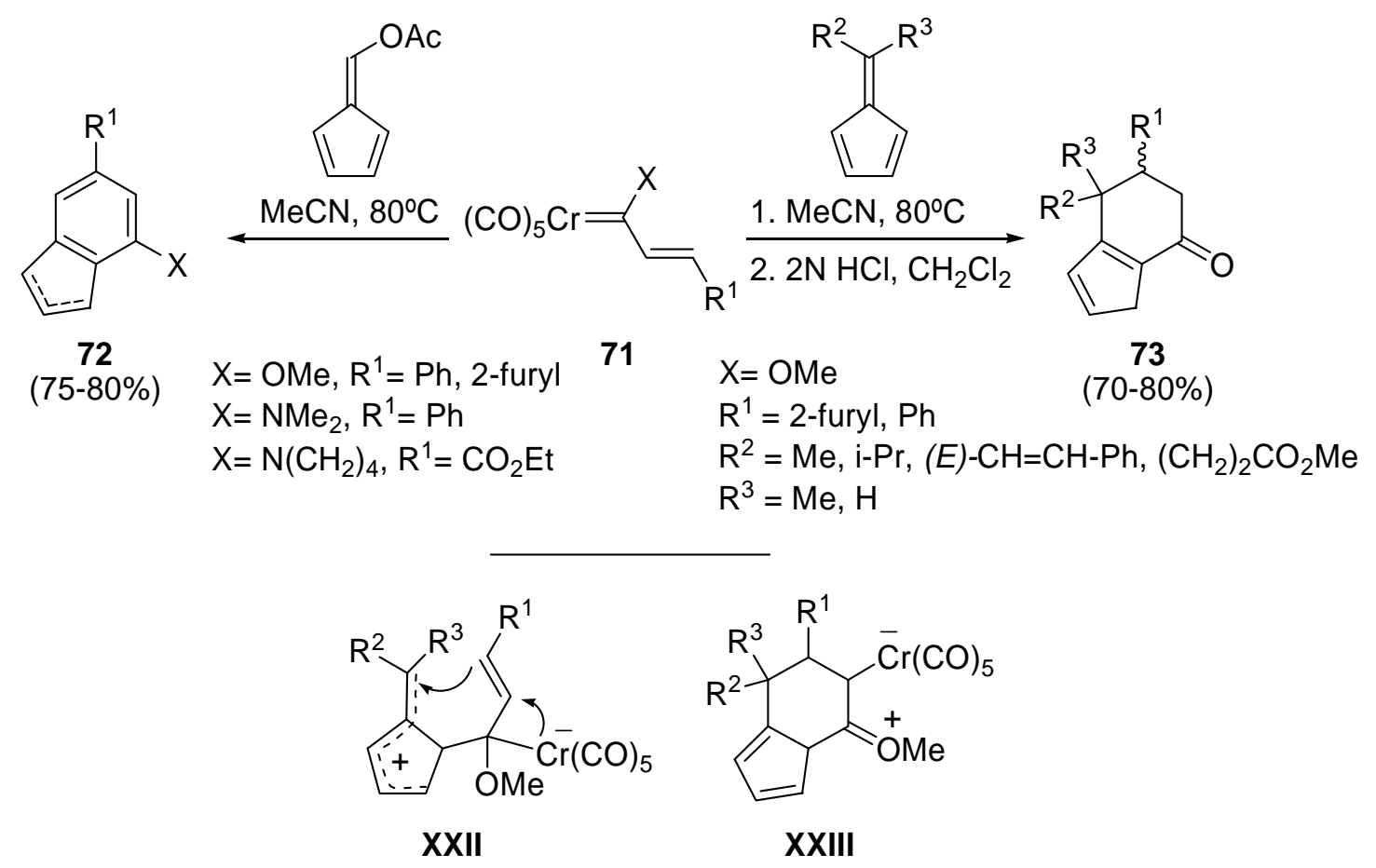

Scheme 23. [6+3] Cyclization of alkenyl carbene complexes and fulvenes.

\section{Acknowledgements}

This research was supported by the Ministerio of Ciencia y Tecnología of Spain (DGICYT, Grants PB94-1313, PB97-1271, BQU-2001-3853 and GE-EXP01-11). Thanks are also given to MECD, FICYT and the European Community for a number of doctoral and postdoctoral fellowships.

\section{References and Notes}

1. Recent reviews: (a) Herndon, J. W. Tetrahedron 2000, 56, 1257. (b) Barluenga, J.; Fañanás, F. J. Tetrahedron 2000, 56, 4597. (c) Sierra, M. A. Chem. Rev. 2000, 100, 3591. (d) de Meijere, A.; Schirmer, H.; Duetsch, M. Angew. Chem., Int. Ed. 2000, 39, 3964. (e) de Meijere, A.; Wu, Y.-T. Topics Organomet. Chem. 2004, 13, 21. (f) Barluenga, J.; Rodriguez, F.; Fañanás, F. J.; Flórez, J. Topics Organomet. Chem. 2004, 13, 59. (g) Barluenga, J.; Fernández-Rodríguez, M. A.; Aguilar, E. J. Organomet. Chem. 2005, 690, 539. (h) Herndon, J. W. Coord. Chem. Rev. 2005, 249, 999. 
2. Barluenga, J.; Aznar, F.; Palomero, M. A.; Barluenga, S. Org. Lett. 1999, 1, 541.

3. Barluenga, J.; Aznar, F.; Palomero, M. A. Angew. Chem., Int. Ed. 2000, 39, 4346.

4. Barluenga, J.; Fernández-Marí, F.; Viado, A. L.; Aguilar, E.; Olano, B.; García-Granda, S.; Moya-Rubiera, C. Chem. Eur. J. 1999, 5, 883.

5. Barluenga, J.; Aznar, F.; Palomero, M. A. Chem. Eur. J. 2001, 7, 5318.

6. Barluenga, J.; Aznar, F.; Barluenga, S.; García-Granda, S.; Alvarez-Rúa, C. Synlett 1997, 1040.

7. Barluenga, J.; Tomás, M.; Ballesteros, A.; Santamaría, J.; Suárez-Sobrino, A. J. Org. Chem. 1997, 62, 9229.

8. Barluenga, J.; Bernardo de la Rúa, R.; de Saá, D.; Ballesteros, A.; Tomás, M. Angew. Chem., Int. Ed. 2005, 44, 2.

9. Barluenga, J.; Tomás, M.; Ballesteros, A.; Santamaría, J.; Carbajo, R. J.; López-Ortíz, F.; García-Granda, S.; Pertierra, P. Chem. Eur. J. 1996, 2, 88.

10. Barluenga, J.; Tomás, M.; Rubio, E.; López-Pelegrín, J. A.; García-Granda, S.; Pertierra, P. J. Am. Chem. Soc. 1996, 118, 695.

11. (a) Barluenga, J.; Montserrat, J. M.; Flórez, J.; García-Granda, S.; Martín, E. Chem. Eur. J. 1995, 1, 236. (b) ibid. Angew. Chem., Int. Ed. 1994, 33, 1392.

12. Barluenga, J.; Diéguez, A.; Rodríguez, F.; Flórez, J.; Fañanás, F. J. J. Am. Chem. Soc. 2002, $124,9056$.

13. Barluenga, J.; Alonso, J.; Fañanás, F. J. J. Am. Chem. Soc. 2003, 125, 2610.

14. Barluenga, J.; Alonso, J.; Fañanás, F. J.; Borge, J.; García-Granda, S. Angew. Chem., Int. Ed. 2004, 43, 5510.

15. Barluenga, J.; Pérez-Sánchez, I.; Rubio, E.; Flórez, J. Angew. Chem., Int. Ed. 2003, 42, 5860 .

16. Barluenga, J.; Martínez, S.; Suárez-Sobrino, A. L.; Tomás, M. J. Am. Chem. Soc. 2002, 124, 5948.

17. Barluenga, J.; Martínez, S.; Suárez-Sobrino, A. L.; Tomás, M. J. Am. Chem. Soc. 2001, 123, 11113. 